\title{
Review and Suggestions about the Education Blank of Contemporary China Sexual Assault Prevention
}

\author{
Pinghan Zha \\ Department of Architectural Engineering \\ Wuhu Institute of Technology \\ Wuhu, Anhui, China 241000
}

\begin{abstract}
The author thinks that in order to make potteryart course teaching impressive, development of pottery-art course in college should combine with its own regional features, school running level and major direction, and fully use existed art resource to adopt its good points and avoid its shortcomings. In recent years, domestic ended with nothing settled sexual assault cases tend to have three common characteristics: acquaintance committing crime; adult victims unable to help themselves, and even become a long-term sex slaves; "secondary victimization" is very serious but it has been ignored. Thereby triggered the explore and review about the contemporary Chinese sexual assault prevention education blank,and point out some targeted suggestions: combined with the latest psychological research findings, rational expansion of judicial, administrative experience and implementation of sexual assault incident handling processes, try to build up a super strong and effective national sexual assault prevention education system in order to fill in the blanks of necessary education and improve the human spirit home construction.
\end{abstract}

Keywords-sexual assault prevention education blank; secondary victimization; rational; psychological research; administrative experience expand; supranational sexual assault prevention education system

\section{INTRODUCTION}

Focus on domestic and abroad sexual assault hard cases in recent years, they often exhibit three common characteristics: first, as the United Nations statistics, many domestic provinces and cities sexual assault survey showed more than $80 \%$ or even $90 \%$ of daytime running rampant perpetrator population is acquaintances (involving ordinary internet friends, fellowtownsman,relatives and friends, teachers and students,colleagues, community neighbors) succeed harm; secondly, regardless of whether the perpetrator and the victim have the premise of in love, the victims from different age,identity, background and experience commonly lack of self rescue ability, so that many victims often continuous suffer physical and psychological humiliation over tens or hundreds of times before they pull off to get out; third is the public seriously lack of rational cognition and human care for such tragedies, especially women victims only mention prosecution according to the law, then without exception they will forced to face "secondary victimization"from different aspects of society in different degrees.
Taiwan media reported a mystery in April 2016,that the "There is a Xinzhu woman in her forties who has suffered over 300 times sexual assault in 6 years, she emphasized because the fear of neighbors gossip and the intimidation of the man,so until now she sued mandatory sexual assault and intimidation. However, the prosecution found that the allegations contrary to common sense, the case finally dispose the prosecution. The public questioned: the plaintiff is voluntarily or mental deficiency? Even it can not be understood in accordance with common sense, the prosecution should not decide not to prosecute so hasty. There must be a reason so they need to make investigation. " the East China Normal University Second High school which with the motto of "Zhuoran Duli, Yueer Shengji" in December 2013 exposed the national Olympiad teacher in sexual assault many outstanding male students in more than 20 years, victim groups after long-term tolerance finally joint appealed and made"wolf teacher" be disciplined. Compare these two cases which suffering a lot of attentions, we find the woman plaintiff in the former case because the potential impact of traditional practices and common rituals, she suffered more doubt after the litigation. However, these two cases obviously have common features: acquaintance commit the crime and the victims long-term loss of effective self-help normal capacity, which we have doubts: the defendant of former case was very easy to get the trial result of "in dubio pro reo "and it has been a common sense, but is the result always fair and reasonable to the conscious injured plaintiff? In both cases, why plaintiffs with different gender, physical and mental characteristics all claimed that they were caught in bad luck and tolerance for many year?Is there a blank in domestic sexual assault prevention education system which rooted in rational debate and modern rule of law for a long time?

\section{DEEP ANALYSIS}

\section{A. Quest based on A Thorough Psychological Research Findings}

After the gradually refine of rational atmosphere and the exchange and collision of Chinese and Western civilizations, the Chinese nation which in different degrees with both elegant and wild appearance has a more progressive social environment than any other era in the past, but not enough to proclaim now living environment has been very harmonious. 
A female victim who deeply has suffered with acquaintance sexual assault crime but can not make litigation. The case accidently experience multi-interference which lead to the deadlock,then the perpetrator's social networking software QQ master page express its master's feeling as "Smile face" plus "knowing afterwards", and in a few years before when he directly facing the case, the same page expressed with its master's feelings according to the time order as "invisible pressure make me so tired ...", "no word", "too SB", "unexpected help " and "hey,not bad,thanks" and so on, you can imagine which thought fragments does the perpetrator going through, at the same time we should be sensitive to the victim's difficult life. The speculative offender in this case after knowing he will not be arrested, and then he said occasionally: "(arrest) colleagues can get different types of girls but I can not", "I was very cunning like a fox". However, the victim who was in unbalanced survival conditions for many years was powerless to make precise forensic for evidence, after suffering for many years finally she got the lightning before death,gradually regain her reading, thinking and memory period, due to chameleon change color to blend in environment, glass lizard cut its tails to escape and such wild and unique natural phenomenon to remember acquaintance was good at confusing others and suddenly harm and all sorts of tricks of violence, but after report to the police, she had to face the unexpected status: she was the only voice under the actual law enforcement environment and the sophisticated perpetrator tried many attempts and finally get away. In fact, the above cases were expected to enhance our cognitive level of the existing psychological research findings and bring the outlook of the further psychology findings.

Psychological science has highly concerned about the psychological development process of the perpetrators, the criminologist Adrian Rehn from University of Pennsylvania had made various brain imaging scans a long time ago for the murderers, violent maniac, psychopath, antisocial personality disorders in prison, and found their brain groove back, nucleus, cortex has structural and functional damages. It is estimated that these brain abnormalities made them not afraid of punishments and their moral judgments also damaged, so they can not understand their behaviors caused emotional harms to others [1].

In addition, how to make comprehensive interpretation of psychological development process of the sexual assault case victims? Emergent cultural neuroscience proved the plasticity of the brain, the importance of social interaction and the diversity of social environment together provide a frame for the diversified development of the human brain in 2012 [2]. Applied Psychology researchers at the University of Vienna in October 2015 found the changing and developing brain structure may be an important factor to influence human intelligence and cognitive ability in a particular period of time. They found the size of brain volume especially the size of hippocampus related with memory, once they are damaged, such as suffering from Alzheimer's disease; it is difficult to remember some recent behaviors and events. May 2016 there was an article on "Neuron" which introduced under the premise of physical and mental healthy,toward four kinds of thinking selections the time for human brain to make the required changes and decisions and the brain changes. "Officer Cai cross the river, saw amphibious crab, so he was overjoyed and said:" crab has eight feet and two claws. "Then he ordered to cook it and after eat it, he threw up and very sick, then he knew it was not crab. Later he told Xie Renzu this story, Xie said:" You did not read 'Erya' so you nearly dead for "Quan Xue". ("Shishuo Xinyu.Pilou") "Ming Dynasty Ma Zhongxi's "Zhongshanlang Zhuan "descried the geek saved wolf but the wolf wanted to eat him, the old man who rescued the geek lied to catch the wolf in bag and killed the ungrateful beast. Officer Cai,Mr.Dongguo and the wolf under non sexual assault state all presented brain hole which effect them to make the right decisions, sexual assault victim groups who did not know all under the control of various historical join force, the crisis moment they inevitably encounter accidents, soon or later they will fell into the perpetrator acquaintance's "fishing"bait, for example, when the heterosexual lover deliberately finding fault and moodiness, they performed passive loss and brain function disorder near collapse [3], the loss of estimated drug sexual assault time and space adaptability,sudden lost original peaceful life and turned into a sexual assault feast with peaceful atmosphere - "essential love structure before whole life marriage[4]" and "warm boiled frog" is not surprising, let alone under the premise of spirit and brain both been damaged, healthy cognitive, memory and choices were transcendence in a dangerous situation. According to foreign media reported on February 14 that Australian man McMahon studied Chinese in High school and he studied in China for a while, but he cannot say fluent Chinese, but after a car accident three years ago, it has a rapid improvement after one week coma.Since then he not only daily conversation and thoughts, even dreams are all raving fluent Chinese, but forgot how to speak English. This deeply worried his parents who can not speak Chinese, they do not know how to communicate with him in the future.Fortunately McMahon could speak English slowly after a few days. The outstanding person in academic circles has a learning experience"use intuition and skip to guess the next research direction [5] ". Unexpected disaster as a special kind of social environment is expected to stimulate benign or malignant liaison contact of brain rich nerve nodes in different victims. Malignant liaison contact of brain rich nerve nodes constituted by A + B (A--one-sided cultural experience before disaster;B--strange and special environmental after disaster)which under the influence of specific survival cultural experience, the conditional maintain may cause a large of number of sexual assault victim groups lost their conventional cognitive ability and routine action force in several years, which lead to they can not make self-rescue, unable to stay away from frequent sexual assault and seek help from reliable groups, and perpetrator groups use the flaw of the law to cover for their crimes and go unpunished.

The culprit for many sexual assault crimes-"Butterfly water", "Obedient water" and other colorless, odorless aphrodisiac drug caused some bad reactions to human body (11)which also worth consult with the drug reaction of Sarin gas which caused the "Gulf War syndrome" in the Middle East and make in-depth discussion: contact or absorption of the Sarin gas this typical nerve toxicant can cause complex symptoms, including paralysis of the human central nervous 
system, convulsions, memory loss, and permanent heart damage after 10 weeks.

Depend on rational proof of relevant psychological research findings, sexual assault case may be able to crack, the involved social phenomenon which so deeply confused the domestic and abroad society with rule and law may get the right medicine.

\section{B. Judicial and Administrative Experiences Need to Expand}

July 2015, the Japanese sex crime penalties related expert seminar had extensively discussion about the promotion of sexual criminal penalties and other issues, they suggested "the sexual assault crime sentencing can not be lighter than robbery", and"sexual assault is the soul level murder, the victim suffered damage will be permanent ","physical and psychological harm of (sexual assault crime) victims and return the deprived property from robbery crime are totoally different matters ","It should gradually strict for sexual assault crime sentencing ". April 2016, the California bill made further steps that it claimed completely eliminate the prosecution limitation of rape and sexual assault cases from next year, and those crimes happened before will no longer have the limitation of prosecution.

At the same time, the domestic judicial rules which contrary to reason is urgently need to corrected: bedisdes sentencing and limitations of prosecution,for many sexual assault cases the inference cognizance of the multiple sexual behaviors between the abuser and the victim are "voluntary" or "forced" often caught in a subjective mistake. Existing legal provisions agreed: "If the man can prove the woman was halfloath and half-consenting, then it will not belong to rape but belong to "in dubio pro reo", its Achilles heel is legislators in a particular era unintentional been controlled by one-sided experience, neither personally understand the whole story of the sexual assault victims (12), but has not been proved by sufficient scientific psychological evidence,so that the perpetrator acquaintances in sexual assault cases accustomed to use idealism brain hole covered by legal language to get away. They were not in love, but he has argued they were; occluded secretly drugging and other control occult, but also discredit the victim was half-loath and half-consenting, the real process maybe one party with dirty motives patiently constructed out the conventional structure of lovemarriage - child (8), effective inspiration of social psychology is before the crime the perpetrator's intentional "love bombing" is often cause the victim's double return, ironically, unmatched with perpetrator's artificial care, encouragement and friendship, the victims actually returned with their sincerely sense of responsibility, indebtedness and guilt, so the victims did not have time to leave and suffered plot, after suffered mental disorder they promised the marriage, but after unconsciously constant sexual assault they finally recognized the truth which confined within two people space remove warmth mask and upgrade the mental torture, if the victims want to run away, then the perpetrator together with other friends and relatives apologize for several years and pretend he did not know the common sense to public in order to get forgiveness,after perpetrator confirmed safety then they will redo delicate master bully and defame the so-called "voluntary sex slaves" Taiwan "Analysis and Discussion on Campus Sexual Assault or Sexual Harassment Case" clearly pointed out after compare all the reported cases "So far all the report cases are true after investigation". [6]Seventies of last century, "Red Queen Evolution Theory" appeared, its core idea is that "you must try to keep running in order to keep you in place"; we ought to discern: For thoses criminals with strong crime profession, the law often is non-perfect, they are cunning and already thinking beyond the limits of existing laws, they communicated through word of mouth or analogy some pitfalls of sexual assault. The long-term multi races mixed occupy caused by several national migrations in history was not able to deny the deep-rooted classical marriage concept of some Chinese people, impose them after they suffered sexual assault they barely need to open the heart tie, their depression barely need to be released, just like they believe the current laws so they have to be calm and peaceful, dancing and singing, their sex life according to "natural selection, survival of the fittest" the individual rules to reconstruct and tend to open are extremely tyranny.

And compared to the two-pronged approach sexual assault incident processing in Hong Kong and Taiwan areas historical practices of "criminal sentences and administrative sanctions could have their own facts", the mainland in addition to temporary absence of administrative sanction process,judicial officers in particular mystery operation commonly manifested as an outsider to this inertia, apathy, omission or interrogate suspected, normally during the process period the perpetrators' relatives ask for favors or exchange of interests and relatives of the victims want to save face, give false testimony, unauthorized private settlement, and drag the case into the ocean. "Mingshizong Shilu", "Guo Chao Xian Zheng Lu", Qing Yu Yue's "Cha Shi San Chao" and Pu Songling's "Liao Zhai Zhi Yi" all have similar stories. In Chenghua period, a senior rogue Sang Chong worship Gu Cai as his teacher, specifically learn how to cheat and sexual assault women without exposure.There were one hundred eighty two victims, later Zhao Wenju see through the truth and reported to the court for detailed investigation, finally the Chenghua emperor ordered to Ling Chi. The social system changes until today, the common citizen shall not send a letter to the top leadership of the big country and request for praising virtue and punishing vice every time they encounter a sexual assault case,but such as anchor Du Fengyi from Fengyang County,Anhui who encountered robbing but because the relative department's disdain action so the Prime has to repeatedly care about it, the similar things are a lot. You can image that some sexual assault victim groups in certain ares often face the difficult positions.The similar humiliation judgment process not only constitute tyranny injury to victims and enshield the perpetrators, but also imperceptibly disobeyed the fair and justice principle of rulelaw in modern society, which is no doubt the lack of humanity to the victims and make it worse. Compare with the basically mature "statistical data of sexual assault and sexual harassment cases' processing basis" in Hong Kong and Taiwan area, the top priority of China mainland is imperative in science, as appropriate, on the basis of deterministic subject of crime targeted design strict judicial and targeted design the strict judicial and administrative sanction procedure based on scientifically 
consider and confirm the subject of sexual crimes,greatly enhance the sense of the rule of law of relative judicial and administrative stuff to prevent and punish sexual assault and earnestly implement the operation rules, form China's public order and good morals of "quick found, quick response, quick processing" to sexual assault cases as soon as possible.

\section{ReVIEWS And Suggestions Of SeXual Assault PREVENTION EDUCATION BLANK}

\section{A. Reviews of Sexual Assault Prevention Education Blank}

On June 3rd 2016, People's Network published Anonymous "Depth Investigation of Child Sexual Abuse Status", it mentioned the working experience of Ye Qian who is the capital child sexual abuse counseling expert: "After the children are sexual abused, it is easy to suffer from anxiety, depression , trauma-specific disorders: acute stress disorder or post-traumatic stress disorder. The long-term serious, sustained, repeated sexual abuse may lead victims get sicker and accompanied with personality changes. A lot of areas are lack of qualified psychological intervention agency, some psychological counseling agencies are very expensive, so the victims are difficult to get effectively help. Psychological counseling agencies set up a special children's psychological trauma treatment center at all levels of the hospitals; schools are equipped with professional psychological teachers,find the problem in time through the popularity of psychological knowledge and daily mental health screening; the creation of specialized institutions and complaints mechanisms to protect girls, from kindergarten to university there are trained female teachers to be responsible for the complaints reception; there are trained female staff specifically in charge of complaints reception in community, village and police station; at the same time build up specified network and telephone assistance channels in order to make the help appealing faster.

Data indicate that victim groups are not limited to children; anyone can become a victim of sexual assault. To be different with robbery or general personal injury, sexual assault victims often face long-term risks, including social withdrawal, posttraumatic stress, depression, eating disorders, personality disorder and suicide. Victimization ratio is: female 1/3, male $1 / 9$, children $1 / 4$. Hong Kong movie star Lan Jieying been drugged and sexual assaulted by a Gangster and lead to her madness; the secretary of the Youth League of a university jumped from the 15th floor before the wedding, it is the bitter fruit of leaders arrange her to be the accompany in drinking and later been brutally raped ; Jan.2016 Taiwan media reported a young girl was raped by her birth father for 134 times but she hide the truth from her birth mother and her elder brother for over six years, until later she her mind gradually mature, she reveal the hidden secrets and make crazy self-mutilation; Australia was called to have relatively relaxed sexual attitude,but when Australian women encounter sexual assault they may decide to make revenge and dragged the dead body for $2 \mathrm{~km}$ without considering the sentence; "poster covering face Photo" news also reflects the US women's long-term protest for governance authorities' understatement processing of sexual assault "Fig.1". Adult victim groups may have the opportunity to step out forgotten, hamartoma, or other obvious fictitious mental disorders in memory and emotion aspects, but they would still have to face the unbalanced mood and destroy from outer world during their surviving and working, there will be a large part of the non victim group continued ignorance on potential dangers- a domestic expert believes that 99 percent of Chinese adults are sex blind, who have not received systematic, standardized and scientific sex education. In 2009, some experts made a survey for 77 health workers in a city's primary and secondary schools about the sexually assault issues, the result indicates that $45.5 \%$ of them knew that children mostly sexual abused by their familiar person; $22.1 \%$ of them knew that after sexual abuse there will not left obvious marks on children's body [7]. In February 2014 a news revealed a usually shy boy climb up the 8th floor and try to rape three women, one of the women are raped, while roommate actually just squat at the corner crying until the police arrive many examples all remind the government to pay attention that only after a large number of adults finished the comprehensive and detailed sexual assault prevention psychology and legal education courses, they would be able to carefully treat themselves and others sexual autonomy, respect and tolerant to the sexual behaviors which does not disturb others,be strict with the sexual behavior which assault others, and make up with a clarity touching humane care to the sexual assault cases caused by the serious lack of sexual assault prevention education[8].
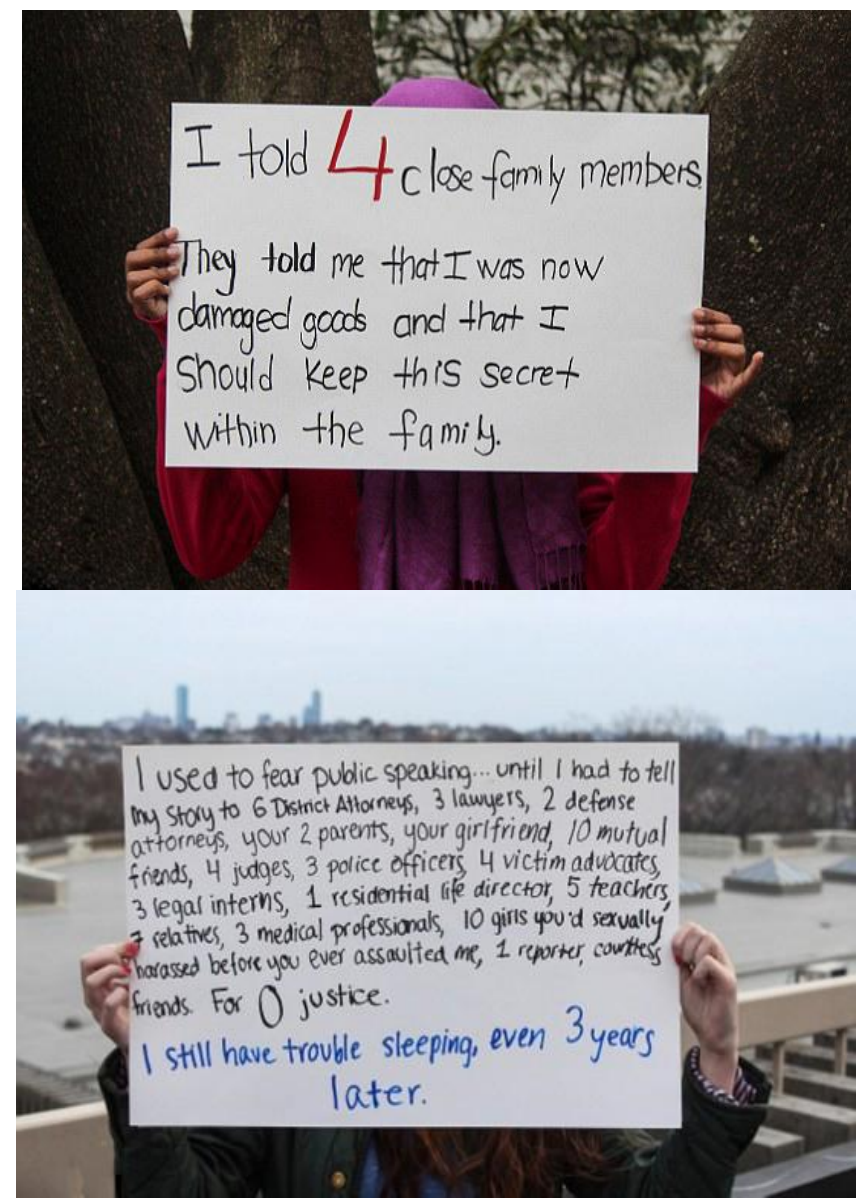

Fig. 1. Poster covering face (Hundreds of US women who suffered sexual assault public their victimi zation experience) 


\section{B. Suggestions}

In nature world, influenza viruses and HIV are able to continue breed and sudden variation, so that the world's most outstanding scientists are facing the challenges. Today there are many "fraud villages" appeared in China, liars who has the twisted sense of worth and sense of right and wrong actually will be ashamed for not cheat people or money. But time and world have changed, a boat sailing against the current must forge ahead or it will be driven back. Faced with growing difficult incidence of sexual assault, strengthen supervision, establish long-term cross-border management agency to scientifically prevent and punish the subject of sexual crimes, avoid some individual old legal provisions became the hotbed of experienced sexual criminals especially those who are good at covered by the local,set up traps, anti-forensic and work on relationships; at the same time, eliminate educational blanks, try to establish powerful and effective websites and communities with supranational function, build up the sexual assault prevention and help system focus on different age groups,clever use of traditional paper media, modern electronic media, mobilize domestic and foreign commonweal organizations uphold love to actively promote love, science, rule of law life pursuit, with the help of a variety of mystery caused by an important factor from the family, community and diverse history together and make regression analysis ( the more the number of traumatic events, more years of schooling or less-subjective level of support) [9], spread to reveal the mystery, thrilling, thought-provoking, cooperation to guarantee the victim groups honestly claim to request the violent suspects' full time participation in polygraph, hypnosis , personality test, rational appeals for sexual crimes depth research. So that we could prevent the crime from the source, reduce crime and improve the spiritual home construction.

\section{CONCLUSION}

The Sexual crime problem is the unspeakable chronic disease which can not be removed in the worldwide and for the long history.Conduct discussion in the scientific filed, adjust and improve the judicial and administrative measures based on comprehensive consideration of human rights protection, actively find and make up sexual assault prevention education blank, and guide good people step into a better and stable world, it is the long-term issue that people who desire for a happy life must be responsible.

\section{REFERENCES}

[1] "Obtained the mysteries of the brain, reduce serious incidents". Guangzhou Daily. August 12, 2012.

[2] Han Shihui, Zhang Yifan. "Social cognition, culture and brain - Cultural neuroscience research" $[\mathrm{J}]$ Journal of Chinese Academy of Sciences , 2012, (Z1): 66-77.

[3] Dominic Streatfeild "Brainwash --- The secret history of mind control" Fourth chapter

[4] Liu Shouping " Ulysses- Model of stream of consciousness novel" Wuhu Institute of Technology, School journal.1999 Volume 1, Issue 3.

[5] Kip Thorne: Crossover talent of Science and art "Academic circle of knowledge society May 2016

[6] Ou Renhao. "analysis and discussion of campus sexual assault or sexual harassment case". Baidu library .96.5.14.
[7] Chen Jingqi. "KAP research of health workers in city's elementary and middle schools for the prevention of child sexual abuse " . China School Health" 2009.

[8] Li Yongjun. "Tolerance and intolerance: the characteristics and trend of sexual adjustment for modern society- study with the perspective of sexual right" . "Rule of law and social development"in 2006.

[9] Sui Shuangge, Chen Liuyue. " Risk factors of urban women suffered sexual assault" "Chinese Mental Health Journal." 2011. 